\title{
Tratamento de Telangiectasias com Laser
}

\author{
Ferreira J. ${ }^{1}$ \\ ${ }^{1}$ Porto Alegre - Brasil. \\ E-mail: drjulioferreira@ibf.med.br
}

Ferreira, J. 2013. Tratamento de Telangiectasias com Laser, p.75. In: Bastos, Francisco Reis. Anais do V Simpósio Internacional de Flebologia [Blucher Medical Proceedings n.1 v.1]. São Paulo: Blucher, 2014

http://dx.doi.org/10.5151/medpro-flebo-SIF_48
As telangiectasias continuam a ser um dos motivos de consulta mais frequentes nos consultórios de Angiologistas e Cirurgiões Vasculares.

Várias técnicas foram propostas para o seu tratamento.

O padrão ouro continua a ser a escleroterapia química, mas em determinadas situações poderá ser necessário utilizar outras técnicas complementares como por exemplo a utilização de Lasers para obter o resultado desejado por médicos e pacientes.

O objetivo desta apresentação será mostrar as principais indicações desta técnica assim como os fundamentos teóricos básicos para poder realizar com sucesso este tipo de tratamento.

Palavras-chave: laser, IVC, varizes, tratamento de varizes. 